\title{
Review \\ Do anti-TNF agents have equal efficacy in patients with rheumatoid arthritis?
}

\author{
Sergio Schwartzman ${ }^{1}$, Roy Fleischmann ${ }^{2}$ and G James Morgan $\mathrm{Jr}^{3}$
}

${ }^{1}$ Hospital for Special Surgery, New York, NY, USA

2University of Texas Southwestern Medical Center, Dallas, TX, USA

${ }^{3}$ Dartmouth-Hitchcock Medical Center, Lebanon, NH, USA

Corresponding author: Sergio Schwartzman (e-mail: schwartzmans@hss.edu)

Received: 29 Sep 2003 Accepted: 30 Oct 2003 Published: 21 Jun 2004

Arthritis Res Ther 2004, 6(Suppl 2):S3-S11 (DOI 10.1186/ar1013)

(c) 2004 BioMed Central Ltd (Print ISSN 1478-6354; Online ISSN 1478-6362)

\begin{abstract}
Tumor necrosis factor (TNF) antagonists have dramatically improved the outcomes of rheumatoid arthritis (RA). Three agents currently available in the USA - infliximab, etanercept, and adalimumab have been designed to modify the biologic effects of TNF. Infliximab and adalimumab are monoclonal antibodies, and etanercept is a soluble protein. The pharmacokinetic and pharmacodynamic properties of each differs significantly from those of the others. All three agents are effective and safe, and can improve the quality of life in patients with RA. Although no direct comparisons are available, clinical trials provide evidence that can be used to evaluate the comparative efficacy of these agents. Infliximab, in combination with methotrexate, has been shown to relieve the signs and symptoms of RA, decrease total joint score progression, prevent joint erosions and joint-space narrowing, and improve physical function for up to 2 years. Etanercept has been shown to relieve the signs and symptoms of $\mathrm{RA}$, decrease total joint score progression, and slow the rate of joint destruction, and might improve physical function. Etanercept is approved with and without methotrexate for patients who have demonstrated an incomplete response to therapy with methotrexate and other disease-modifying antirheumatic drugs (DMARDs), as well as for first-line therapy in early RA, psoriatic arthritis, and juvenile RA. Adalimumab relieves the signs and symptoms of RA with and without methotrexate and other DMARDs, decreases total joint score progression, prevents joint erosions and joint-space narrowing in combination with methotrexate, and might improve physical function. When selecting a TNF antagonist, rheumatologists should weigh evidence and experience with specific agents before a decision is made for use in therapy.
\end{abstract}

Keywords: adalimumab, efficacy, etanercept, infliximab, rheumatoid arthritis

\section{Introduction}

Rheumatoid arthritis (RA), a systemic disease, is the most common form of inflammatory arthritis [1]. The disorder has a worldwide prevalence of about $1 \%$ and an annual incidence of 3 per 10,000 adults $[2,3]$; it is more common in women than in men [2]. RA is accompanied by significant morbidity and mortality. Depending on the severity of the disease at onset, the risk of disability can be as high as $33 \%$, and mortality can be increased by as much as $52 \%$, frequently as a result of infection or circulatory disease [4].
As might be expected, patients with RA also have a significant impairment in their quality of life (QOL) [5].

The ultimate goals of treatment are the prevention or control of joint damage, the prevention of functional loss, and the relief of pain [6]. With the earlier and more aggressive use of disease-modifying anti-rheumatic drugs (DMARDs) and with the introduction of the tumor necrosis factor (TNF) antagonists during the past 5 years, the management of RA has changed markedly. Previously, treat-

$\mathrm{ACR}=$ American College of Rheumatology; ARMADA = Anti-TNF Research Study Program of the Monoclonal Antibody D2E7 in Patients With RA; ATTRACT = Anti-TNF Trial in RA With Concomitant Therapy; CRP = C-reactive protein; DMARDs = disease-modifying anti-rheumatic drugs; ESR = erythrocyte sedimentation rate; $\mathrm{HAQ}=$ Health Assessment Questionnaire; IL = interleukin; $\mathrm{QOL}=$ quality of life; $\mathrm{RA}=$ rheumatoid arthritis; s.c. = subcutaneously; TNF = tumor necrosis factor. 
ment was organized in a therapeutic pyramid, in which conservative management with nonsteroidal anti-inflammatory drugs was administered for several years, followed by the addition of DMARDs in a slow and incremental fashion once radiographic evidence of bony erosions appeared [1]. Unfortunately, this approach was associated with increased morbidity, lost productivity, decreased life expectancy, and increased healthcare costs. Today, treatment with DMARDs alone, or in combination, and with TNF biologic response modifiers is initiated early in patients with RA who are at an increased risk for progressive disease $[1,7,8]$. The 2001 World Health Organization Collaborating Centre consensus meeting on anti-cytokine therapy guidelines identified appropriate patients eligible for anti-cytokine therapy as patients with active RA who have failed an adequate course of DMARD therapy [8]. In these guidelines, unacceptable disease activity was defined as five swollen joints plus an elevated acute-phase response such as an erythrocyte sedimentation rate (ESR) of more than $28 \mathrm{~mm} / \mathrm{h}$ or a C-reactive protein (CRP) concentration of more than $20 \mathrm{mg} / \mathrm{l}$, whereas adequate exposure was defined as a course of methotrexate at a dose of at least $20 \mathrm{mg} /$ week for 3 months or a smaller dose if toxicity is a limiting factor [8]. The international consensus guidelines have provided useful additional evidence-based recommendations $[9,10]$.

Infliximab (Remicade ${ }^{\circledR}$; Centocor, Inc., Malvern, PA, USA), etanercept (Enbrel ${ }^{\circledR}$; Immunex Corp, Seattle, WA, USA), and adalimumab (Humira ${ }^{\mathrm{TM}}$; Abbott Laboratories, Abbott Park, IL, USA) are designed to modulate the inflammatory cascade of RA by binding TNF, thereby decreasing its bioavailability. Various cytokines have been detected in the synovial fluid of patients with RA, both pro-inflammatory (namely TNF, interleukin-1 [IL-1], and IL-6) and anti-inflammatory (transforming growth factor- $\beta$ and IL-10) [11]. With several cytokines involved in the cytokine network of RA, it was argued that the suppression of only one mediator in a cytokine network might not be sufficient to control the pathophysiologic process underlying the disease [11].

Early studies by Brennan and colleagues demonstrated that in a synovial cell culture system the secondary synthesis of IL-1 and other cytokines could be markedly reduced by targeting TNF $[11,12]$. This led to more active research in this direction. In summary, the role of TNF is based on (1) its ability to degrade cartilage and bone in vitro, (2) its arthritogenic properties in animal models, (3) the colocalization of its receptors in RA synovium and the pannus-cartilage junction, and (4) its central role in regulating the synthesis of IL-1 in cultured RA-derived synovial cells $[13,14]$.

Infliximab, etanercept, and adalimumab have undergone extensive clinical trials that have shown them to be effica- as TNF biologic response modifiers, these agents possess distinct pharmacokinetic and pharmacodynamic profiles. In the absence of any directly comparative trials, this article seeks to place the various considerations of their efficacy in perspective. It focuses on how these agents have fared in terms of their effects on symptoms (assessed by American College of Rheumatology [ACR] response criteria), structure (based on erosion, joint-space narrowing, and Sharp scores), and physical function/QOL (based on standardized questionnaires such as the Health Assessment Questionnaire [HAQ]).

\section{Etanercept}

Etanercept is a fusion protein consisting of the ligandbinding portion of the human p75 TNF receptor plus the Fc fragment of human IgG1 [15]. Etanercept has a terminal half-life of $102 \pm 30$ hours [15]. The recommended starting dose is $25 \mathrm{mg}$ subcutaneously (s.c.) twice weekly, with or without methotrexate [15].

In a multicenter, double-blind, placebo-controlled, phase II trial, 180 patients with refractory RA were randomized to one of four groups: etanercept $0.25,2$, or $16 \mathrm{mg} / \mathrm{m}^{2}$ s.c., or placebo twice weekly for 3 months [16]. The primary efficacy measure was the percentage change in swollen joint count, tender joint count, and total count of swollen and tender joints from baseline to study end point (3 months) [16]. The data were then analyzed to determine the number of patients who attained the ACR criteria for 20\% improvement (ACR20) and 50\% improvement (ACR50). ACR20 is defined as a $20 \%$ improvement in tender and swollen joint counts and at least three of the following disease activity variables: patient's assessment of pain, patient's global assessment of disease activity, physician's global assessment of disease activity, patient's assessment of physical function, and ESR or CRP concentration [17]. Treatment with etanercept resulted in significant dose-related reductions in disease activity. After 3 months, improvements in ACR20 criteria were demonstrated in $75 \%$ of patients in the group with the highest dose $\left(16 \mathrm{mg} / \mathrm{m}^{2}\right)$, compared with $14 \%$ of controls $(P<0.001)$. Additionally, the mean percentage reduction in the number of tender or swollen joints was significantly greater in the etanercept $16 \mathrm{mg} / \mathrm{m}^{2}$ group than in the controls $(61 \%$ versus $25 \%, P<0.001)$. There were no significant safety issues. The authors concluded that monotherapy with etanercept for 3 months is safe, well tolerated, and associated with clinical improvement in the symptoms of RA.

Moreland and colleagues evaluated the efficacy of $10 \mathrm{mg}$ and $25 \mathrm{mg}$ doses of etanercept by using the primary efficacy end points of improvements in disease activity as determined by ACR20 and ACR50 criteria at 3 and 6 months [18]. This randomized, placebo-controlled trial involved 234 American and Canadian patients with active 
RA who had demonstrated an inadequate response to DMARD therapy. The number of patients who attained the ACR criteria for $70 \%$ improvement (ACR70) and changes in scores for swollen and tender joints were also assessed at the specified time intervals. Etanercept produced a significant dose-related improvement in disease manifestation. At 3 months, a significantly greater percentage of patients in the etanercept $25 \mathrm{mg}$ group achieved ACR20 and ACR70 responses than did controls $(62 \%$ versus $23 \%, P<0.001$ [ACR20], and $41 \%$ versus $8 \%$, $P<0.001$ [ACR50]) [18]. At 6 months, a significantly greater percentage of patients who received etanercept $25 \mathrm{mg}$ met the ACR20 and ACR50 criteria than did controls $(59 \%$ versus $11 \%, P<0.001$ [ACR20] and $40 \%$ versus $5 \%, P<0.001$ [ACR50]) [18]. Similarly, improvements in ACR20 and ACR50 scores were reported in a significantly greater percentage of patients who received etanercept $10 \mathrm{mg}$ than controls $(51 \%$ versus $11 \%$, $P<0.001$ [ACR20] and 24\% versus 5\%, $P<0.001$ [ACR50]). Other 6-month results showed that mean counts of tender and swollen joints were significantly reduced in the patients who received etanercept $25 \mathrm{mg}$ compared with controls (56\% versus $6 \%, P<0.05 ; 47 \%$ versus $7 \%, P<0.05$, respectively) [18]. Finally, significantly more etanercept-treated patients achieved an ACR70 response than did controls. At 6 months, 15\% of patients in the etanercept $25 \mathrm{mg}$ group, $9 \%$ of patients in the etanercept $10 \mathrm{mg}$ group, and $1 \%$ of patients in the placebo group had achieved ACR70 response $(P<0.031$ for each etanercept group compared with the placebo group) [18]. Etanercept was well tolerated, and the investigators concluded that etanercept monotherapy could safely provide rapid, significant, and sustained benefits in patients with active RA.

The long-term efficacy and safety of etanercept monotherapy in patients with DMARD-refractory RA have also been demonstrated in open-label extension studies lasting up to 5 years $[19,20]$. Patients from a previous long-term safety trial, in which etanercept monotherapy was investigated in adults who had not responded satisfactorily to at least one DMARD, have been followed for up to 4.3 years (median, 2.4 years) for a total of 1336 patient-years [19]. Results are now available for 479 adult patients who received etanercept as monotherapy for more than 1 year, 420 patients who received the drug for more than 2 years, 164 patients who received the drug for more than 3 years, and 12 patients who received the drug for more than 4 years [19].

Patients were evaluated by ACR criteria for disease activity. At 3.5 years, $69 \%, 50 \%$, and $25 \%$ of patients had achieved ACR20, ACR50, and ACR70 responses, respectively [19]. Moreland and colleagues reported their observations on the efficacy and safety of up to 5 years of etanercept therapy in patients with RA on the basis of the experience of participants in North American trials of etan- ercept who decided to enroll in open-label extension studies [20]. Data on long-term efficacy were available from 159 patients who had been evaluated for more than 4 years. The results showed that $28 \%$ of these patients had no tender joints, $24 \%$ had no swollen joints, and $21 \%$ had HAQ disability scores of 0 units [20]. Safety data, which were derived from 1442 patients who had been receiving etanercept for up to 5 years, showed an overall low rate of adverse events. The frequency of infections requiring hospitalization or intravenous antibiotics was 0.04 per patient-year in the total population (3573 patientyears), equivalent to the rate in placebo groups in controlled trials [20].

The efficacy of etanercept in combination with methotrexate has been evaluated in randomized, double-blind, placebo-controlled, and open-label extension studies $[21,22]$. Weinblatt and colleagues conducted a 6 -month randomized, placebo-controlled, double-blind trial of etanercept $25 \mathrm{mg}$ s.c. twice weekly plus methotrexate in 89 patients with persistently active RA despite at least 6 months of methotrexate therapy at a stable dosage of 10-25 mg/week [21]. The primary efficacy measure was the percentage of patients who met ACR20 criteria at 24 weeks. Patients treated with the combination experienced rapid and sustained improvement. At 6 months, the ACR 20 criteria were met by $71 \%$ of patients treated with the combination of etanercept and methotrexate but by only $27 \%$ of patients treated with methotrexate plus placebo $(P<0.001)$. Furthermore, the ACR50 criteria were met by $39 \%$ of the patients treated with etanercept plus methotrexate but by only $3 \%$ of the patients treated with methotrexate plus placebo $(P<0.001)$.

The patients who received etanercept plus methotrexate had significantly better outcomes according to other measures of disease activity. At 24 weeks, the ACR70 response criteria were met by $15 \%$ of the group receiving etanercept plus methotrexate, versus $0 \%$ of the methotrexate plus placebo group $(P=0.03)$ [21]. Also at 24 weeks, patients in the etanercept plus methotrexate group had median counts of tender joint of 7 versus 17 in the methotrexate plus placebo group; these were improvements from baseline of $75 \%$ and $39 \%$, respectively, in which patients had a median of 28 tender joints. Further, those in the etanercept plus methotrexate group had a median count of 6 swollen joints versus 11 in the methotrexate plus placebo group; these were improvements from baseline of $78 \%$ and $33 \%$, respectively, in which patients had a median of 18 swollen joints [21]. For the HAQ data at 24 weeks, there was a $47 \%$ improvement (from median values of 1.5 units at baseline to 0.8 unit at the end of the study) in the etanercept plus methotrexate group, and there was a $27 \%$ improvement (from median values of 1.5 units at baseline to 1.1 units at the end of the study) in the methotrexate plus placebo group [21]. 
Adverse events included mild injection-site reactions, which occurred significantly more often in the etanercept plus methotrexate group than in the methotrexate plus placebo group (42\% versus $7 \%, P<0.001)$ [21]. Overall, infection (for example upper respiratory tract infections or sinusitis) was the most common adverse event, but there were no significant intergroup differences in incidence or type of infection [21].

The benefits of etanercept plus methotrexate were further confirmed in a long-term trial that involved 79 of the 89 patients who had previously participated in the trial discussed earlier [22]. Of the 79 patients who originally enrolled, 14 withdrew and 65 patients remained on therapy for a median of 44 months (maximum 47 months) [22]. A reduction in the doses of methotrexate and steroids was allowed after patients had received at least 3 months of etanercept in addition to methotrexate. As permitted by the protocol, $62 \%$ of the 66 patients assessed at 3 years either reduced (from $17.5 \mathrm{mg} /$ week at baseline to $11.0 \mathrm{mg} /$ week, a $37 \%$ mean reduction; $P<0.0001)$ or discontinued their methotrexate dosage, with 29\% of patients discontinuing methotrexate [22]. Among the patients receiving steroids, 3-year data showed $83 \%$ of patients had a reduction (from baseline of $6.4 \mathrm{mg} /$ day to $2.4 \mathrm{mg} /$ day, a $63 \%$ mean reduction; $P<0.0001$ ), with $56 \%$ of patients discontinuing steroids [22]. There was sustained improvement of disease activity, based on ACR response criteria, in patients treated with etanercept even though methotrexate and steroid doses were reduced or their use was discontinued.

Data from 57 patients evaluated for efficacy showed that $77 \%, 47 \%$, and $23 \%$ of patients met ACR20, ACR50, and ACR70 criteria, respectively, after 3 years of therapy [22]. These studies indicate that etanercept plus methotrexate produces clinically significant and long-term benefits in patients with persistently active RA.

In addition to improving outcomes in patients with chronic RA, etanercept has been demonstrated to be of benefit in patients with early RA. In the Early Rheumatoid Arthritis trial, which consisted of a 1 -year blinded phase $(n=632)$ [23] and a 1-year open-label extension phase $(n=512)$ [24], etanercept 10 or $25 \mathrm{mg}$ s.c. twice weekly was compared with methotrexate (mean dosage $19 \mathrm{mg} /$ week) in patients with active early RA (mean duration less than 3 years). ACR criteria were employed to assess treatment efficacy in terms of clinical response. The percentages of patients in the group assigned to receive etanercept $25 \mathrm{mg}$ who had ACR20, ACR50, and ACR70 responses were significantly greater than those in the methotrexate group at most evaluations within the first 6 months $(P<0.05)$ but were approximately the same thereafter [23]. At 12 months, $72 \%$ of the patients in the group response, as compared with $65 \%$ of patients in the methotrexate group $(P=0.16)$ [23].

In the same trial, investigators compared the effects of etanercept and methotrexate on radiographic evidence of disease progression. Bone erosion and joint-space narrowing were measured radiographically and scored with the Sharp scale, in which an increase of 1 unit represents one new erosion or minimal narrowing [23-27]. The Sharp score is the sum of the erosion scores (based on a sixpoint scale of 0 to 5 at 46 joints) and joint-space narrowing scores (based on a five-point scale of 0 to 4 at 42 joints). In this trial the Sharp score ranged from 0 (no damage) to 398 (severe joint destruction) [23,25-27]. The 12-month data from the blinded phase showed less radiographic evidence of bone erosion in the etanercept $25 \mathrm{mg}$ group than in the methotrexate group (the mean increase in erosion score was 0.47 versus 1.03 units, $P=0.002$ ) [23]. There were no significant differences between the groups in progression of joint-space narrowing [23]. Patients in the etanercept $25 \mathrm{mg}$ group had mean Sharp scores of $12.4 \pm 15.8$, whereas patients in the methotrexate group had mean Sharp scores of $12.9 \pm 13.8[23,24]$. At 6 months the mean total Sharp scores increased by 0.57 unit in the etanercept $25 \mathrm{mg}$ group and by 1.06 units in the methotrexate group $(P=0.001)$. At 12 months, mean total Sharp scores increased by 1.00 unit in the etanercept $25 \mathrm{mg}$ group and by 1.59 units in the methotrexate group $(P=0.11)$ [23]. Data from the open-label phase showed that, at 24 months, etanercept was more effective than methotrexate in arresting structural damage on the basis of mean increases in total Sharp scores (1.3 versus 3.2 units, $P=0.001)$ and erosion scores (0.7 versus 1.9 units, $P=0.001$ ) [24]. Effects of etanercept and methotrexate on joint-space narrowing at the end of 24 months were comparable (Fig. 1) [24,28].

In terms of physical function, a similar percentage of patients in the etanercept and methotrexate groups (about $55 \%$ ) demonstrated an improvement in HAQ score of at least 0.5 unit at 1 year. The same proportion of etanercept-treated patients (55\%) but a lower percentage of methotrexate-treated patients (37\%) maintained improvement for up to 2 years $(P<0.001)$ (Fig. 2) [24]. As a point of reference, a change in $\mathrm{HAQ}$ score must equal at least 0.22 unit to be considered clinically significant [29].

Another study showing that etanercept led to a sustained improvement in disease activity, as determined by reduction in $\mathrm{HAQ}$ scores, was conducted by Fleischmann and colleagues [30]. In this analysis, improvements in HAQ disability scores over 2 years were compared between 207 patients with early RA (mean duration 1 year) and 563 patients with long-standing (late) RA (mean duration 12 years), who were treated with etanercept $25 \mathrm{mg}$ s.c. 
Figure 1

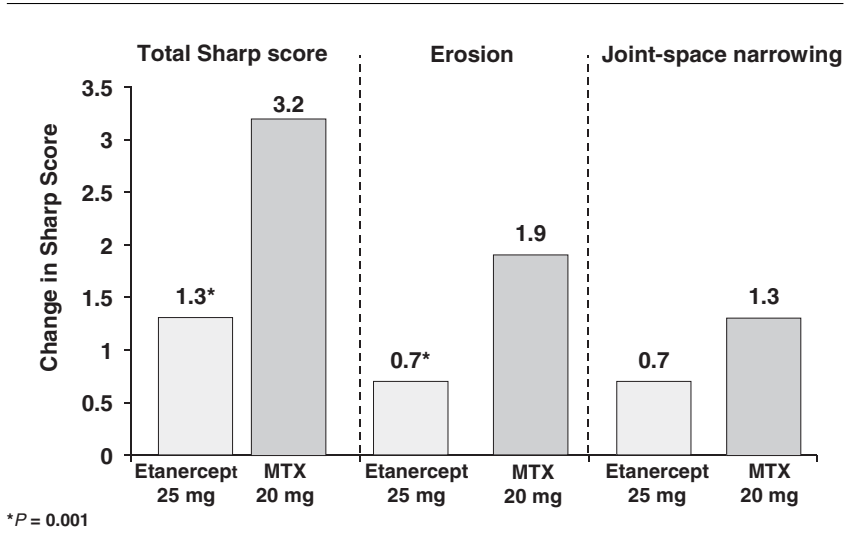

Changes in total Sharp score, erosion, and joint-space narrowing at 2 years in patients who had early rheumatoid arthritis (RA) and were given etanercept or methotrexate (MTX). These were the data from the open-label extension phase of the Early Rheumatoid Arthritis trial [28].

\section{Figure 2}

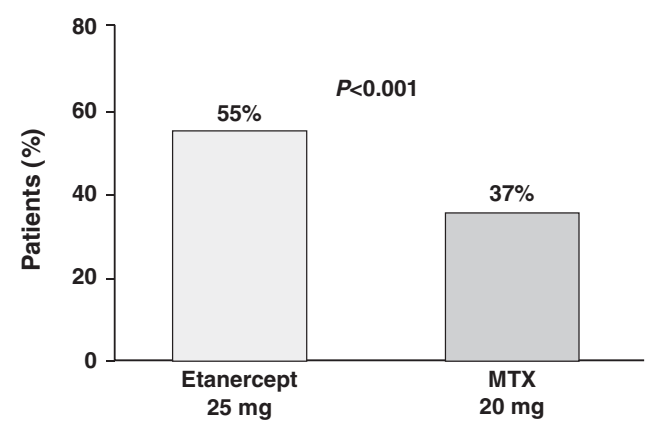

Improvement of at least 0.5 unit in health assessment questionnaire score at 2 years in patients who had early rheumatoid arthritis and were given etanercept or methotrexate (MTX). This was an open-label trial. Reproduced with permission from John Wiley \& Sons, Inc. [24].

(C) 2002 American College of Rheumatology

twice weekly [30]. Mean baseline patient characteristics for the early RA and late RA groups were similar, including age (51 versus 53 years), HAQ (1.5 versus 1.6 units), tender joint count (31 versus 32 ), swollen joint count (24 versus 26), CRP concentration (3.3 versus $4.4 \mathrm{mg} / \mathrm{dl}$ ), and presence of rheumatoid factor (87\% versus $81 \%)$; those with early disease had been treated with fewer DMARDs (0.5 versus 3.3) [30].

Results at 2 years showed that mean HAQ scores declined in both the early RA (from 1.5 to 0.6 unit) and late RA (from 1.6 to 1.0 unit) groups. A greater percentage of patients with early disease achieved HAQ scores of 0 units, compared with those who had late disease (29\% versus $14 \%$, $P<0.001$ ) [30]. The study concluded that aggressive therapy has a greater potential to improve disability, as measured by $\mathrm{HAQ}$, in patients with early $\mathrm{RA}$ than in
Figure 3

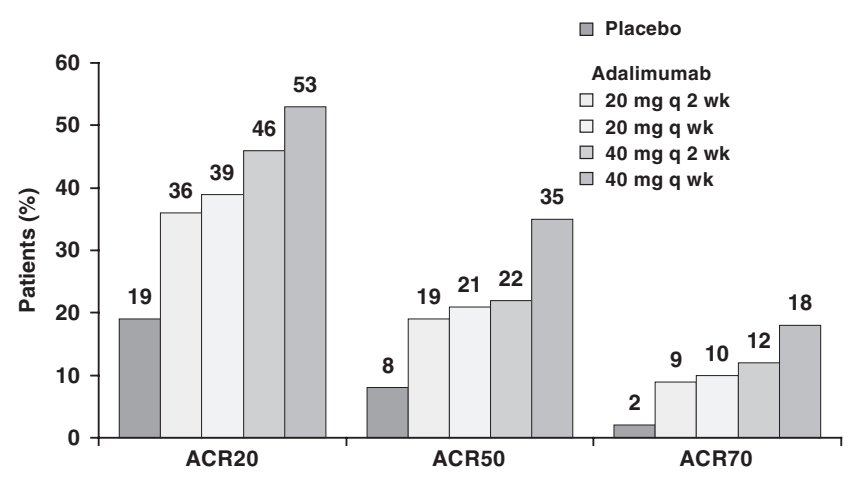

Increases in ACR20, ACR50, and ACR70 scores in patients with rheumatoid arthritis who failed previous disease-modifying antirheumatic drug therapy and were given one of four dosages of adalimumab or placebo. Adapted with permission from the BMJ Publishing Group [32].

patients with more established or late RA who have not responded satisfactorily to multiple DMARDs [30].

\section{Adalimumab}

Adalimumab, also known as D2E7, is a fully human recombinant lgG1 anti-TNF monoclonal antibody [31]. Adalimumab is available as a preparation that is administered s.c. every 2 weeks [31]. Studies indicate that adalimumab is effective and safe as biologic therapy for patients with $\mathrm{RA}$, with and without methotrexate or in combination with other DMARDs.

Van de Putte and colleagues studied the efficacy and safety of adalimumab in a phase III, placebo-controlled, double-blind, 26-week trial involving 544 patients with RA who had failed treatment with one or more DMARDs [32]. After a DMARD washout period of 4 weeks, patients were randomized to one of five groups: adalimumab 20 or 40 mg s.c. weekly or biweekly, or placebo. Baseline demographics were similar for all groups. Treatment with adalimumab produced dose-related and schedule-related disease improvements measured by ACR20, ACR50, and ACR70 response criteria, with the monoclonal antibody demonstrating superiority to placebo at all dosages (Fig. 3) [32]. Adalimumab was safe and well tolerated, with the most common adverse events being injection-site reactions (9.7\%), rash (9.4\%), and headache (9.4\%) [32].

Adalimumab plus methotrexate has been shown to be efficacious in patients who demonstrated a partial response to methotrexate alone. The Anti-TNF Research Study Program of the Monoclonal Antibody D2E7 in Patients With RA (ARMADA) study was a 24-week, randomized, double-blind, placebo-controlled, dose-ranging trial in which 271 patients with RA were administered adalimumab 20,40 , or $80 \mathrm{mg}$ s.c. every 2 weeks plus 
methotrexate (mean dosage $16.8 \mathrm{mg} /$ week) or placebo $[33,34]$. Efficacy measures included the proportion of patients who attained an ACR20 response at 24 weeks (primary end point) as well as the proportion of those who met ACR50 and ACR70 response criteria at the end of the study [34].

An ACR20 response at 24 weeks was attained by a significantly greater percentage of patients in the 20,40 , and $80 \mathrm{mg}$ adalimumab plus methotrexate groups (47.8\%, $67.2 \%$, and $65.8 \%$, respectively) than in the placebo plus methotrexate group $(14.5 \%)(P<0.001)$ [34]. ACR50 response rates were attained by a significantly greater percentage of patients in the 20,40, and $80 \mathrm{mg}$ adalimumab groups $(31.9 \%, 55.2 \%$, and $42.5 \%$, respectively) than in the placebo group $(8.1 \%)(P=0.003, P<0.001$, $P<0.001$, respectively) [34]. ACR 70 response rates were attained by a significantly greater percentage of patients in the 40 and $80 \mathrm{mg}$ adalimumab groups (26.9\% and $19.2 \%$, respectively) than in the placebo group (4.8\%) $(P<0.001$ and $P<0.02)$ [34]. There were also clinically significant improvements in $\mathrm{HAO}$ and physical function, where the baseline scores for the $20,40,80 \mathrm{mg}$, and placebo groups were 1.52, 1.55, 1.55, and 1.64 units, respectively [34]. At 24 weeks, the HAQ data showed mean reductions in scores of $0.54,0.62$, and 0.59 unit for the adalimumab 20,40, and $80 \mathrm{mg}$ groups, respectively, compared with 0.27 for the placebo group ( $P=0.004, P<0.001, P<0.001$, respectively) [34].

After completing the 6-month (24-week) double-blind portion of the ARMADA trial, 250 of the original 271 patients entered an open-label extension study that evaluated the efficacy and safety of the combination of adalimumab and methotrexate over 12 months [35]. All patients received adalimumab $40 \mathrm{mg}$ s.c. every other week in combination with methotrexate; 231 of the 250 patients completed 12 months of treatment [35]. Mean baseline patient characteristics were as follows: age, 55.1 years; gender, $75.6 \%$ female; positivity for rheumatoid factor, $81 \%$; duration of RA, 12.5 years; number of previous DMARDs used, 3 ; and methotrexate dosage, $16.8 \mathrm{mg} /$ week [35].

Results showed that when adalimumab was given to partial responders to methotrexate, clinical efficacy was sustained throughout 12 months [35]. At 12 months, the ACR20, ACR50, and ACR70 response rates for the adalimumab $40 \mathrm{mg}$ group were $71.2 \%, 50.8 \%$, and $26.0 \%$, respectively [35]. With regard to QOL data at 12 months, the adalimumab $40 \mathrm{mg}$ group showed a decline of 0.6 unit from baseline, which indicates that the initial response was maintained for the entire 12 months [34,35].

In a 52-week, double-blind, placebo-controlled trial involving 619 patients with active RA, treatment with adali-
Figure 4

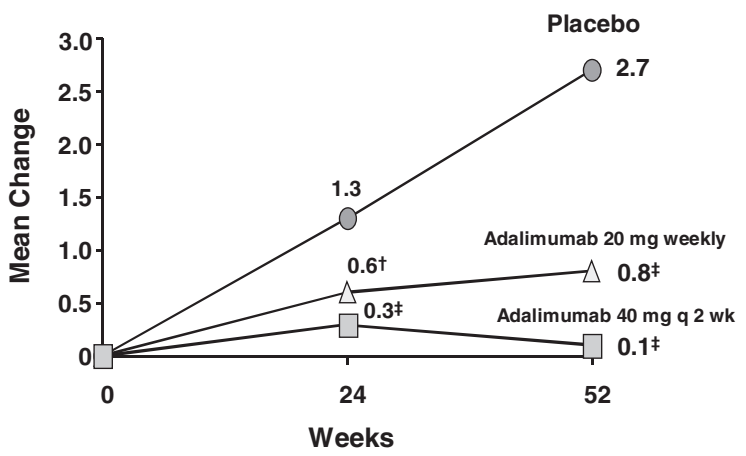

tP 0.01 vs. placebo

$\ddagger P 0.001$ vs. placebo

Changes in total Sharp score in patients with active rheumatoid arthritis who were given one of two dosages of adalimumab or placebo. Reproduced with permission from John Wiley \& Sons, Inc. [36]. (c) 2002 American College of Rheumatology

joint damage in patients with active RA who had an incomplete response to methotrexate therapy [36]. Patients were randomized to receive adalimumab s.c. $40 \mathrm{mg}$ biweekly or $20 \mathrm{mg}$ weekly, or placebo. Treatment with methotrexate (mean baseline dosage $16.6 \mathrm{mg} /$ week) was initiated and continued with no change in dose over the course of the study. After 1 year there was a significant response in clinical measures of disease activity in the adalimumab-treated patients and significant differences in radiographic end points between the adalimumab-treated and placebo groups. Mean increases in the Sharp score for the adalimumab 20 and $40 \mathrm{mg}$ and placebo groups were $0.8,0.1$, and 2.7 , respectively $(P \leq 0.001$ versus placebo) (Fig. 4) [36]. There was a significant decrease in both joint erosions and joint-space narrowing. Thus, compared with methotrexate alone, treatment with adalimumab plus methotrexate inhibits the progression of structural joint disease in patients with RA.

Adalimumab has been shown to be efficacious in patients who have failed previous DMARD therapy or have demonstrated incomplete responses to a variety of DMARDs, including methotrexate. In addition, adalimumab has been shown to inhibit radiographically evident disease progression. In each of these studies there was a significant improvement in physical function and $\mathrm{QOL}$ in patients for up to 1 year. Because the US Food and Drug Administration (FDA) requires at least 2 years of data showing improvement, adalimumab has not yet been approved for this indication $[35,36]$.

\section{Infliximab}

Infliximab is a chimeric $\lg G 1-\kappa$ monoclonal antibody against TNF produced by recombinant DNA technology in 
a continuously perfused cell line [37]. Unlike etanercept, infliximab does not bind lymphotoxin- $\alpha$ [38]: it binds both the monomeric and trimeric forms of the inflammatory cytokine TNF, forming a stable molecular complex with both molecular species. Infliximab must be administered by intravenous infusion and has a terminal half-life of 8-10 days. In managing patients with RA, the recommended dose of infliximab is $3 \mathrm{mg} / \mathrm{kg}$ initially, followed by similar doses at weeks 2 and 6 , then every 8 weeks thereafter. This regimen can be adjusted by increasing the dose to $10 \mathrm{mg} / \mathrm{kg}$ and/or shortening the intervals between doses to as often as every 4 weeks to optimize patient response [37]. As of February 2002, infliximab has been administered to more than 271,000 patients (data on file, Centocor, Inc.). Infliximab in combination with methotrexate is the only regimen so far approved by the FDA for reducing symptoms, inhibiting structural damage, and improving physical function in patients with moderate-tosevere RA [37].

The efficacy and safety of infliximab in patients with RA has been demonstrated in the Anti-TNF Trial in RA With Concomitant Therapy (ATTRACT) study [39-41] and several earlier studies [42-46]. ATTRACT was a 2-year, multicenter, multinational trial of 428 patients with active RA despite methotrexate therapy. The patients were randomized to one of five regimens: infliximab 3 or $10 \mathrm{mg} / \mathrm{kg}$ intravenously every 4 or 8 weeks, or placebo [39]. All patients continued to receive a stable dose of methotrexate (median $15 \mathrm{mg} /$ week for at least 6 months; range $10-35 \mathrm{mg} /$ week). At 30 weeks, $50 \%$ of patients who received infliximab $3 \mathrm{mg} / \mathrm{kg}$ every 8 weeks met the ACR20 response criteria, compared with $20 \%$ of placebo recipients $(P<0.001)$ [39]. At 54 weeks, a greater percentage of patients who received infliximab $3 \mathrm{mg} / \mathrm{kg}$ every 8 weeks met ACR20, ACR50, and ACR70 response criteria than controls $(42 \%$ versus $17 \%, P<0.001$ [ACR20]; $21 \%$ versus $8 \%, P=0.027$ [ACR50]; and $10 \%$ versus $2 \%$, $P=0.04$ [ACR70]) [40]. These improvements in the infliximab-treated patients, compared with the controls, were sustained for up to 102 weeks (42\% versus $16 \%$, $P<0.001$ [ACR20]; $21 \%$ versus $6 \%, \quad P=0.003$ [ACR50]; and $10 \%$ versus $1 \%, P=0.008$, respectively [ACR70]) [41]. Patients who received the infliximab $10 \mathrm{mg} / \mathrm{kg}$ regimens also showed superior improvement in ACR20, ACR50, and ACR70 response, compared with controls, for up to 102 weeks [41].

Results from the ATTRACT study indicated that infliximab halts the progression of structural joint disease and can even improve some radiographic parameters. At 54 weeks, patients treated with methotrexate plus placebo demonstrated evidence of increased joint damage, with a mean change in total Sharp score of 7 units [40]. This finding is consistent with that of other studies of structural joint damage in patients receiving DMARDs. However,
Figure 5

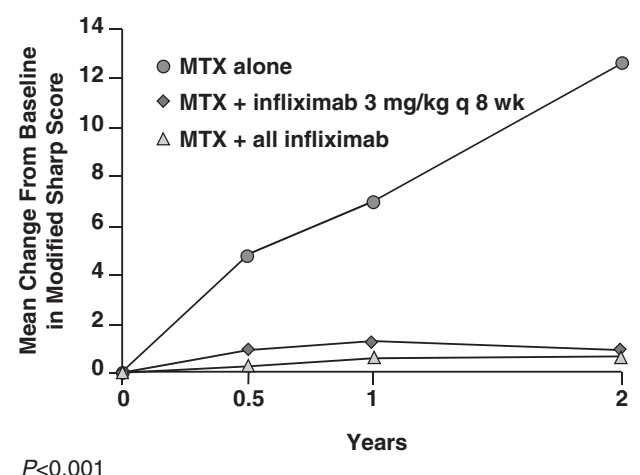

Changes in modified Sharp score in patients with active rheumatoid arthritis despite methotrexate (MTX) therapy who were given MTX alone or in combination with infliximab (the Anti-Tumor Necrosis Factor Trial in Rheumatoid Arthritis With Concomitant Therapy [ATTRACT] study) [39-41].

patients treated with infliximab showed no evidence of progressive joint damage and had a mean change in total Sharp score of 0.6 unit by 54 weeks $(P<0.001)$ [40]. The durability of this benefit was confirmed in the 102-week ATTRACT data (Fig. 5) [39-41].

Two-year follow-up data from the ATTRACT study showed that infliximab inhibits structural damage in RA patients with moderately-to-severely active disease as assessed by the Sharp score, bone erosion scores, and joint-space narrowing scores [39-41].

In ATTRACT, all regimens (doses/schedules) of infliximab plus methotrexate showed significantly greater improvement from baseline in HAQ and the Medical Outcomes Study Short Form Health Survey (SF-36) physical component summary score averaged over time through week 54 compared with placebo plus methotrexate $[37,40]$. In terms of the median (interquartile range) improvement from baseline through week 54 in $\mathrm{HAQ}$, was $0.4(0.1,0.9)$ for the infliximab groups compared with $0.1(-0.1,0.5)$ for the placebo plus methotrexate group [37]. The favorable effects on HAQ and SF-36 were sustained through week 102 [37]; all infliximab-treated patients at that time showed a median improvement in $\mathrm{HAQ}$ of 0.3 versus 0.1 for placebo treated patients, $P<0.001$ [41].

\section{Conclusion}

RA causes significant functional morbidity accompanied by pain, suffering, and an impaired QOL [47]. The TNF antagonists represent a significant advance in the therapy of active RA. The three members of this class - infliximab, etanercept, and adalimumab - have shown efficacy in inhibiting joint destruction over various lengths of time, reducing symptoms, and improving physical function in 
patients with RA. However, they have distinct clinical, pharmacokinetic, and pharmacodynamic properties that must be considered when selecting a drug for therapy. An integral component of the decision-making process regarding choice of therapy is patient preference. Other factors include published evidence documenting the overall experience with each drug, the duration of each trial in which the drugs were studied, the type of statistical analysis employed, and patient factors such as disease duration, disease severity at baseline, and the use of previous and concomitant medications. Careful consideration of all these clinical variables and appropriate use of the newer additions to the antirheumatic armamentarium such as the TNF biologic response modifiers will, it is hoped, contribute to better outcomes for patients with RA.

\section{Competing interests}

SS is a speaker for Centocor, Abbott and Boehringer. RF is a consultant, on the Speaker's Bureau, and performed clinical studies for Centocor, Immunex, Amgen, Wyeth and Abbott. GJM is a consultant for Centocor, and on the Speaker's Bureau for Abbott and Centocor.

\section{Acknowledgement}

The transcript of the World Class Debate for ACR 2002 has been published electronically in Joint and Bone. This article, and others published in this supplement, serve as a summary of the proceedings as well as a summary of other supportive, poignant research findings (not included in the World Class Debate ACR 2002).

\section{References}

1. Lee DM, Weinblatt ME: Rheumatoid arthritis. Lancet 2001, 358: 903-911.

2. Spector TD: Rheumatoid arthritis. Rheum Dis Clin North Am 1990, 16:513-537.

3. Silman AJ, Pearson JE: Epidemiology and genetics of rheumatoid arthritis. Arthritis Res 2002, 4(Suppl 3):S265-S272.

4. Mikuls TR, Saag KG, Criswell LA, Merlino LA, Kaslow RA, Shelton $\mathrm{BJ}$, Cerhan JR: Mortality risk associated with rheumatoid arthritis in a prospective cohort of older women: results from the lowa Women's Health Study. Ann Rheum Dis 2002, 61: 994-999.

5. Lapsley HM, March LM, Tribe KL, Cross MJ, Courtenay BG, Brooks PM: Living with rheumatoid arthritis: expenditures, health status, and social impact on patients. Ann Rheum Dis 2002, 61:818-821.

6. American College of Rheumatology Subcommittee on Rheumatoid Arthritis Guidelines: Guidelines for the management of rheumatoid arthritis: 2002 update. Arthritis Rheum 2002, 46: 328-346.

7. Wolfe F, Cush JJ, O'Dell JR, Kavanaugh A, Kremer JM, Lane NE, Moreland LW, Paulus HE, Pincus T, Russell AS, Wilskie KR: Consensus recommendations for the assessment and treatment of rheumatoid arthritis. J Rheumatol 2001, 28:14231430.

8. Emery P, Reginster JY, Appelboom T, Breedveld FC, Edelmann E, Kekow J, Malaise M, Mola EM, Montecucco C, Sanda M, Sany J, Scott DL, Serni U, Seydoux G: WHO Collaborating Centre consensus meeting on anti-cytokine therapy in rheumatoid arthritis. Rheumatology (Oxford) 2001, 40:699-702.

9. Maetzel A, Tugwell P, Boers M, Guillemin F, Coyle D, Drummond $M$, Wong JB, Gabriel SE: Economic evaluation of programs or interventions in the management of rheumatoid arthritis: defining a consensus-based reference case. I Rheumatol 2003, 30:891-896.

10. Emery P: Is it time for a European consensus on the pharmacological management of early RA? J Rheumatol Supp/ 2002, 66:1-2.
11. Eigler A, Sinha B, Hartmann G, Endres S: Taming TNF: strategies to restrain this proinflammatory cytokine. Immunol Today 1997, 18:487-492.

12. Brennan FM, Maini RN, Feldmann M: TNF alpha - a pivotal role in rheumatoid arthritis? $\mathrm{Br} J$ Rheumatol 1992, 31:293-298.

13. Feldmann $\mathrm{M}$ : What is the mechanism of action of anti-tumour necrosis factor- $\alpha$ antibody in rheumatoid arthritis? Int Arch Allergy Immunol 1996, 111:362-365.

14. Maini RN, Feldmann M: How does infliximab work in rheumatoid arthritis? Arthritis Res 2002, 4(Suppl 2):S22-S28.

15. Medical Economics Company Inc: Prescribing information: Enbrel ${ }^{\circledR}$. In Physicians' Desk Reference ${ }^{\circledR}$. Montvale, NJ: 2002:3504-3507.

16. Moreland LW, Baumgartner SW, Schiff MH, Tindall EA, Fleischmann RM, Weaver AL, Ettlinger RE, Cohen S, Koopman WJ, Mohler K, Widmer MB, Blosch CM: Treatment of rheumatoid arthritis with a recombinant human tumor necrosis factor receptor (p75)-Fc fusion protein. $N$ Engl J Med 1997, 337:141-147.

17. Felson DT, Anderson JJ, Boers M, Bombardier C, Chernoff M, Fried B, Furst D, Goldsmith C, Kieszak S, Lightfoot R (The Committee on Outcome Measures in Rheumatoid Arthritis Clinical Trials): The American College of Rheumatology preliminary core set of disease activity measures for rheumatoid arthritis clinical trials. Arthritis Rheum 1993, 36:729-740.

18. Moreland LW, Schiff MH, Baumgartner SW, Tindall EA, Fleischmann RM, Bulpitt KJ, Weaver AL, Keystone EC, Furst DE, Mease PJ, Ruderman EM, Horwitz DA, Arkfeld DG, Garrison L, Burge DJ, Blosch CM, Lange MLM, McDonnell ND, Weinblatt ME: Etanercept therapy in rheumatoid arthritis. A randomized, controlled trial. Ann Intern Med 1999, 130:478-486.

19. Moreland LW, Cohen SB, Baumgartner SW, Schiff MH, Tindall $E A$, Burge DJ: Long-term use of Enbrel ${ }^{\circledR}$ (etanercept) in patients with DMARD-refractory rheumatoid arthritis. Presented at the 2nd Annual European Congress of Rheumatology (EULAR) 2001, Prague, the Czech Republic, on 15 June 2001.

20. Moreland LW, Cohen S, Fleischmann RM, Baumgartner SW, Schiff MH, Burge DJ: Safety and efficacy of up to 5 years of etanercept $\left(E n b r e l^{\circledR}\right)$ therapy in rheumatoid arthritis. Presented at the 3rd Annual European Congress of Rheumatology (EULAR) 2002, Stockholm, Sweden, on 14 June 2002.

21. Weinblatt ME, Kremer JM, Bankhurst AD, Bulpitt KJ, Fleischmann RM, Fox RI, Jackson CG, Lange M, Burge DJ: A trial of etanercept, a recombinant tumor necrosis factor receptor:Fc fusion protein, in patients with rheumatoid arthritis receiving methotrexate. N Engl J Med 1999, 340:253-259.

22. Kremer JM, Weinblatt ME, Bankhurst AD, Bulpitt KJ, Fleischmann RM, Jackson CG, Atkins KM, Feng A, Burge DJ: Etanercept added to background methotrexate therapy in patients with rheumatoid arthritis: continued observations. Arthritis Rheum 2003, 48:1493-1499.

23. Bathon JM, Martin RW, Fleischmann RM, Tesser JR, Schiff MH, Keystone EC, Genovese MC, Wasko MC, Moreland LW, Weaver $\mathrm{AL}$, Markenson J, Finck BK: A comparison of etanercept and methotrexate in patients with early rheumatoid arthritis. $N$ Engl J Med 2000, 343:1586-1593.

24. Genovese MC, Bathon JM, Martin RW, Fleischmann RM, Tesser JR, Schiff MH, Keystone EC, Wasko MC, Moreland LW, Weaver AL, Markenson J, Cannon GW, Spencer-Green G, Finck BK: Etanercept versus methotrexate in patients with early rheumatoid arthritis: two-year radiographic and clinical outcomes. Arthritis Rheum 2002, 46:1443-1450.

25. Plant MJ, Saklatvala J, Borg AA, Jones PW, Dawes PT: Measurement and prediction of radiological progression in early rheumatoid arthritis. J Rheumatol 1994, 21:1808-1813.

26. Sharp JT: Scoring radiographic abnormalities in rheumatoid arthritis. Radiol Clin North Am 1996, 34:233-241.

27. Van Der Heijde D, Simon L, Smolen J, Strand V, Sharp J, Boers M, Breedveld F, Weisman M, Weinblatt M, Rau R, Lipsky P: How to report radiographic data in randomized clinical trials in rheumatoid arthritis: guidelines from a roundtable discussion. Arthritis Rheum 2002, 47:215-218.

28. Genovese M, Martin RW, Fleischmann R, Keystone E, Bathon J, Spencer-Green G, Finck B: Enbrel ${ }^{\circledR}$ (etanercept) vs. methotrexate (MTX) in early rheumatoid arthritis (ERA trial): two-year follow up. Presented at the 2nd Annual European Congress of Rheumatology (EULAR) 2001, Prague, the Czech Republic, on 16 June 2001. 
29. Wells GA, Tugwell P, Kraag GR, Baker PRA, Groh J, Redelmeier DA: Minimum important difference between patients with rheumatoid arthritis: the patient's perspective. J Rheumatol 1993, 20:557-560.

30. Fleischmann R, Baumgartner S, Moreland L, Schiff M, Markenson J, Spencer-Green G: Improvement of disability in RA patients with early vs established disease after treatment with Enbrel ${ }^{R}$ (etanercept). Presented at the 2nd Annual European Congress of Rheumatology (EULAR) 2001, Prague, the Czech Republic, on 15 June 2001.

31. Abbott Laboratories: Humira: package insert. Abbott Park, IL; 2002.

32. de Putte LBA, Rau R, Breedveld FC, Kalden JR, Malaise MG, van Riel PLCM, Schattenkirchner M, Emery P, Burmester GR, Zeidler $\mathrm{H}$, Montsopoulos HM, Beck K, Kupper H: Efficacy and safety of the fully human anti-tumour necrosis factor $\alpha$ monoclonal antibody adalimumab (D2E7) in DMARD refractory patients with rheumatoid arthritis: a 12 week, phase II study. Ann Rheum Dis 2003, 62:1168-1177.

33. Keystone $E$, Weinblatt ME, Weisman M, Furst D, Paulus $H$ Birbara C, Fischkoff S, Chartash EK: The fully human anti-TNF monoclonal antibody, adalimumab (D2E7), dose ranging study: the 24-week clinical results in patients with active RA on methotrexate (the ARMADA trial). Presented at the 2nd Annual European Congress of Rheumatology (EULAR) 2001, Prague, the Czech Republic, on 15 June 2001.

34. Weinblatt ME, Keystone EC, Furst DE, Moreland LW, Weisman $\mathrm{MH}$, Birbara CA, Teoh LA, Fischkoff SA, Chartash EK: Adalimumab, a fully human anti-tumor necrosis factor alpha monoclonal antibody, for the treatment of rheumatoid arthritis in patients taking concomitant methotrexate: the ARMADA trial. Arthritis Rheum 2003, 48:35-45.

35. Kavanaugh AF, Weinblatt M, Keystone E, Furst DE, Moreland LW, Teoh L, Fischkoff S, Chartash E: The ARMADA trial: 12-month efficacy and safety of combination therapy with adalimumab (D2E7), the first fully human anti-TNF monoclonal antibody, and methotrexate (MTX) in patients with active rheumatoid arthritis. Presented at the 3rd Annual European Congress of Rheumatology (EULAR) 2002, Stockholm, Sweden, on 14 June 2002.

36. Keystone E, Kavanaugh AF, Sharp J, Hua Y, Teoh L, Fischkoff S, Chartash E: Adalimumab (D2E7), a fully human anti-TNF- $\alpha$ monoclonal antibody, inhibits the progression of structural joint damage in patients with active RA despite concomitant methotrexate therapy. Arthritis Rheum 2002, 46 (9 Suppl): S205.

37. Centocor, Inc.: Remicade: package insert, revised June 2002. Malvern, PA; 2002.

38. Scallon B, Cai A, Solowski N, Rosenberg A, Song XY, Shealy D, Wagner C: Binding and functional comparisons of two types of tumor necrosis factor antagonists. J Pharmacol Exp Ther 2002, 301:418-426.

39. Maini R, St Clair EW, Breedveld F, Furst D, Kalden J, Weisman M, Smolen J, Emery P, Harriman G, Feldmann M, Lipsky P, for the ATTRACT Study Group: Infliximab (chimeric anti-tumour necrosis factor $\alpha$ monoclonal antibody) versus placebo in rheumatoid arthritis patients receiving concomitant methotrexate: a randomised phase III trial. Lancet 1999, 354: 1932-1939.

40. Lipsky PE, van der Heijde DMFM, St Clair EW, Furst DE, Breedveld FC, Kalden JR, Smolen JS, Weisman M, Emery P, Feldmann M, Harriman GR, Maini RN, for the Anti-Tumor Necrosis Factor Trial in Rheumatoid Arthritis With Concomitant Therapy Study Group: Infliximab and methotrexate in the treatment of rheumatoid arthritis. N Engl J Med 2000, 343:1594-1602.

41. Lipsky $P$, van der Heijde D, St Clair W, Furst D, Kalden J, Weisman M, Breedveld F, Emery P, Keystone E, Harriman G, Maini R: The ATTRACT Investigators. 102-week clinical and radiologic results from the ATTRACT trial: a 2-year, randomized, controlled, phase 3 trial of infliximab (Remicade ${ }^{\circledR}$ ) in patients with active RA despite MTX. Arthritis Rheum 2000, 43 (Suppl 9):1216.

42. Elliott MJ, Maini RN, Feldmann $M$, Long-Fox $A$, Charles $P$, Katsikis P, Brennan FM, Walker J, Bijl H, Ghrayeb J, Woody JN: Treatment of rheumatoid arthritis with chimeric monoclonal antibodies to tumor necrosis factor $\alpha$. Arthritis Rheum 1993, 36: 1681-1690.
43. Elliott MJ, Maini RN, Feldmann M, Long-Fox A, Charles P, Bijl H, Woody JN: Repeated therapy with monoclonal antibody to tumour necrosis factor alpha (cA2) in patients with rheumatoid arthritis. Lancet 1994, 344:1125-1127.

44. Elliott MJ, Maini RN, Feldmann M, Kalden JR, Antoni C, Smolen JS, Leeb B, Breedveld FC, Macfarlane JD, Bijl H, Woody JN: Randomised double-blind comparison of chimeric monoclonal antibody to tumour necrosis factor $\alpha$ (cA2) versus placebo in rheumatoid arthritis. Lancet 1994, 344:1105-1110.

45. Kavanaugh A, St Clair EW, McCune WJ, Braakman T, Lipsky P: Chimeric anti-tumor necrosis factor- $\alpha$ monoclonal antibody treatment of patients with rheumatoid arthritis receiving methotrexate therapy. J Rheumato/ 2000, 27:841-850.

46. Maini RN, Breedveld FC, Kalden JR, Smolen JS, Davis D, Macfarlane JD, Antoni C, Leeb B, Elliott MJ, Woody JN, Schaible TF, Feldmann M: Therapeutic efficacy of multiple intravenous infusions of anti-tumor necrosis factor $\alpha$ monoclonal antibody combined with low-dose weekly methotrexate in rheumatoid arthritis. Arthritis Rheum 1998, 41:1552-1563.

47. Allaire SH, Prashker MJ, Meenan RF: The costs of rheumatoid arthritis. Pharmacoeconomics 1994, 6:513-522.

\section{Correspondence}

Sergio Schwartzman MD, Hospital for Special Surgery, 535 East 70th Street, New York, NY 10021, USA. Tel: +1 212606 1557; fax: +1 212794 2527; e-mail: schwartzmans@hss.edu 